\title{
Synthesis of poly(p-phenylene-vinylene) derivative having amphiphilic substituents by palladium-catalyzed three-component coupling polymerization of p-bromophenylallene and nucleophile containing oligo- oxyethylene units
}

\author{
Seiji Kannoo, Takashi Saruhashi, Satoko Ishibe, Kojiro Nakagawa, and \\ Ikuyoshi Tomita(四) \\ Department of Electronic Chemistry, Interdisciplinary Graduate School of Science and \\ Engineering, Tokyo Institute of Technology, Nagatsuta-cho 4259-G1-9, Midori-ku, Yokohama, \\ 226-8502 Japan \\ E-mail: tomita@echem.titech.ac.jp; Fax: +81-45-924-5489
}

Received: 27 April 2006 / Accepted: 20 July 2006

Published online: 7 August 2006 - @ S Springer-Verlag 2006

\section{Summary}

The palladium-catalyzed three-component coupling polymerization of $\mathrm{p}$ bromophenylallene and a nucleophile possessing oligo-oxyethylene units was performed to give a poly( $p$-phenylene-vinylene) derivative having amphiphilic substituents on each vinylene unit in a high yield. The polymer was found to be soluble in organic solvents such as benzene, chloroform, $N, N$-dimethylformamide, and methanol, whose number-average molecular weight $\left(M_{\mathrm{n}}\right)$ and the molecular weight distribution $\left(M_{\mathrm{w}} / M_{\mathrm{n}}\right)$ were estimated as 8,600 and 1.76 , respectively.

\section{Introduction}

Step-growth polymerizations such as polycondensation processes are important synthetic methods to obtain functional and high-performance polymers. These polymerization processes are usually composed of very simple reactions between two kinds of building blocks. Therefore, it is often required to perform complicated monomer synthetic processes to attain designed synthesis of polymers having objective structures and properties. For example, poly(p-phenylene-vinylene) and its derivatives (PPV's), which are important $\pi$-conjugated polymers applicable to electronic and luminescent devices, are obtainable by the polycondensation methods on the basis of the transition metal-catalyzed cross-coupling processes [1]. The only way to obtain PPV's with good solubility and processability is to design monomers by incorporation of soft lateral substituents.

As an alternative approach to obtain polymers with highly functionalized repeating units, we have been working on the development and applications of novel threecomponent polycondensation systems that enable to connect three kinds of building 
blocks at once [2,3]. For example, on the basis of the palladium-catalyzed threecomponent coupling reaction [4], we have described the polymerization of aromatic bisallenes, aryl dihalides, and nucleophiles or of halophenylallenes and nucleophiles which proved to be effective to design PPV's having functional groups on each vinylene unit $[2 \mathrm{~b}, 2 \mathrm{~d}]$.

To demonstrate the possibility of this three-component polycondensation to achieve the macromolecular design of PPV's and to control their properties such as solubility, we would like to describe the synthesis of a derivative of PPV possessing amphiphilic oligo-oxyethylene lateral groups on each vinylene unit (3) by using a nucleophile possessing oligo-oxyethylene chains (2) for the palladium-catalyzed three-component coupling polymerization with p-bromophenylallene (1) (Scheme 1).

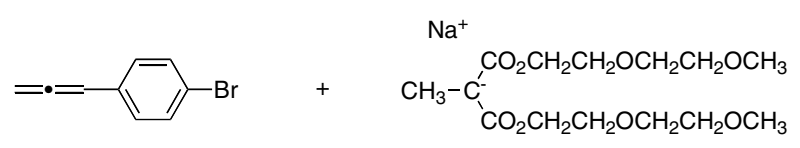

1

2

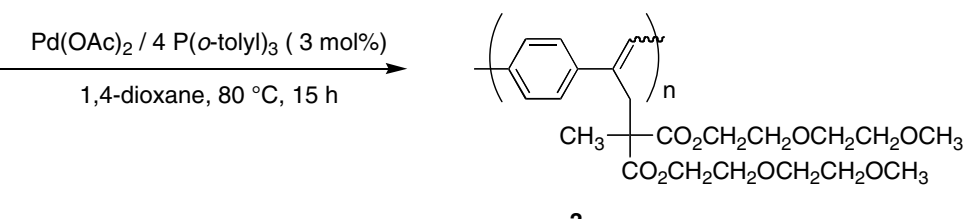

3

Scheme 1. Synthesis of a poly(p-phenylene-vinylene) derivative by the three-component coupling polymerization of $\mathbf{1}$ and $\mathbf{2}$.

\section{Experimental}

\section{Material}

Phenylallene and p-bromophenylallene (1) were prepared as previously reported and were purified by distillation under reduced pressure $\left(62{ }^{\circ} \mathrm{C} / 12 \mathrm{mmHg}\right.$ and $75{ }^{\circ} \mathrm{C} / 1.0$ $\mathrm{mmHg}$, respectively) [5]. Tetrahydrofuran (THF), hexane, and 1,4-dioxane were dried over sodium benzophenone ketyl and distilled under nitrogen. Bromobenzene was distilled prior to use. Tri-o-tolylphosphine $\left(\mathrm{P}(o \text {-tolyl })_{3}\right)$ was purified by recrystallization from EtOH. Other reagents were used as received. All the reactions and the polymerization were carried out under nitrogen.

\section{Instruments}

Nuclear magnetic resonance (NMR) spectra were recorded on a JEOL ECP-300 instrument using tetramethylsilane as an internal standard $(300 \mathrm{MHz}$ and $75 \mathrm{MHz}$ for ${ }^{1} \mathrm{H}-\mathrm{NMR}$ and ${ }^{13} \mathrm{C}-\mathrm{NMR}$, respectively). Fourier transform infrared (IR) spectra were recorded on a JASCO FT/IR-5300 instrument. UV-vis spectra were obtained on a Shimadzu UV-3100PC spectrophotometer. Photoluminescence spectra were measured 
on a Shimadzu RF-5300PC spectrophotomerter. Gel permeation chromatography (GPC) measurements were performed on a Shimadzu LC-10AS equipped with Tosoh TSK-gel $\mathrm{GMH}_{\mathrm{HR}}-\mathrm{M}$ tandem columns using $\mathrm{CHCl}_{3}$ as an eluent at $35^{\circ} \mathrm{C}$. Polystyrene standards were used for calibration.

\section{Synthesis of sodium bis(methoxyethoxyethyl) methylmalonate (2)}

In a flask equipped with a Dean-Stark apparatus, the mixture of methylmalonic acid (1.8 g, $15 \mathrm{mmol})$, methoxyethoxyethanol (4.0 g, $33 \mathrm{mmol})$, p-toluenesulfonic acid $(0.57 \mathrm{~g}, 3.0 \mathrm{mmol})$, and benzene $(250 \mathrm{~mL})$ were heated under reflux for $24 \mathrm{~h}$. After removal of the volatile factions under reduced pressure, the purification by column chromatography on $\mathrm{SiO}_{2}$ (eluent: ethyl acetate) gave bis(methoxyethoxyethyl) methylmalonate in a 93\% yield $(4.5 \mathrm{~g}, 14 \mathrm{mmol}) .{ }^{1} \mathrm{H}-\mathrm{NMR}\left(\mathrm{CDCl}_{3}, \delta, \mathrm{ppm}\right): 1.44(\mathrm{~d}$, $\left.J=7.2 \mathrm{~Hz}, 3 \mathrm{H}, \mathrm{CH}_{3}-\mathrm{CH}<\right), 3.33-3.73\left(12 \mathrm{H}+6 \mathrm{H}+1 \mathrm{H},-\mathrm{CH}_{2}-\mathrm{O}-,-\mathrm{O}-\mathrm{CH}_{3}, \mathrm{C}-\mathrm{CH}(\mathrm{COO}-)_{2}\right)$, $4.31\left(\mathrm{~m}, 4 \mathrm{H},-\mathrm{COO}-\mathrm{CH}_{2}-\right) .{ }^{13} \mathrm{C}-\mathrm{NMR}\left(\mathrm{CDCl}_{3}, \delta, \mathrm{ppm}\right): 13.6,45.9,59.0,64.4,68.8$, 70.5, 71.8, 170.0. IR $\left(\mathrm{NaCl}, \mathrm{cm}^{-1}\right): 2882,1734,1456,1381,1358,1327,1250,1200$, $1165,1111,1044,943,864$.

The treatment of the ester thus obtained with $\mathrm{NaH}$ provided the nucleophile (2) as follows: to a flask equipped with a dropping funnel and a magnetic stirrer bar, was added $\mathrm{NaH}$ ( $55 \mathrm{wt} \%$ in oil, $0.52 \mathrm{~g}, 12 \mathrm{mmol}$ ) and was washed three times with hexane. After the removal of the remaining solvent under reduced pressure, THF $(20 \mathrm{~mL})$ was introduced to the flask and a THF $(20 \mathrm{~mL})$ solution of bis(methoxyethoxyethyl) methylmalonate $(3.83 \mathrm{~g}, 11.9 \mathrm{mmol})$ was added slowly from the dropping funnel and the resulting mixture was kept stirring for an additional $4 \mathrm{~h}$ at ambient temperature. After filtration and evaporation of the volatile fractions under reduced pressure, the viscous oil remained was washed successively with hexane and the remaining oil was dissolved in benzene. The nucleophile (2) was obtained as in essentially pure form as a benzene-soluble part.

\section{Synthesis of model compounds (4)}

To a flask equipped with a magnetic stirrer bar, a benzene solution of $2(0.60 \mathrm{M}, 3.4$ $\mathrm{mL}, 2.0 \mathrm{mmol}$ ) was introduced and the solvent was removed in vacuo. Then, palladium acetate $\left(\mathrm{Pd}(\mathrm{OAc})_{2}, 0.0068 \mathrm{~g}, 0.030 \mathrm{mmol}\right), \mathrm{P}(o \text {-tolyl })_{3}(0.036 \mathrm{~g}, 0.12$ $\mathrm{mmol})$, and 1,4-dioxane $(2.0 \mathrm{~mL})$ were added and the mixture was stirred for $10 \mathrm{~min}$. After addition of bromobenzene $(0.16 \mathrm{~g}, 1.0 \mathrm{mmol})$ and phenylallene $(0.12 \mathrm{~g}, 1.0$ mmol), the reaction mixture was heated at $80{ }^{\circ} \mathrm{C}$ for $15 \mathrm{~h}$. To the resulting mixture, water was added and was extracted three times with diethyl ether. After drying over magnesium sulfate, the product was isolated by column chromatography on $\mathrm{SiO}_{2}$ (eluent: ethyl acetate) to give stilbene derivatives (4) as a mixture of $E$ - and $Z$-isomers in an $89 \%$ yield $(0.46 \mathrm{~g}, 0.89 \mathrm{mmol}) .{ }^{1} \mathrm{H}-\mathrm{NMR}\left(\mathrm{CDCl}_{3}, \delta, \mathrm{ppm}\right): 1.17(3 \mathrm{H} \times 0.53$, $\left.\mathrm{CH}_{3^{-}},(E)\right), 1.38\left(3 \mathrm{H} \times 0.47, \mathrm{CH}_{3^{-}},(Z)\right), 3.22-3.59\left(12 \mathrm{H}+2 \mathrm{H}+6 \mathrm{H},-\mathrm{CO}_{2}-\mathrm{C}_{-} \mathrm{CH}_{2}-\mathrm{O}-\right.$ $\left.\mathrm{CH}_{2} \mathrm{CH}_{2}-\mathrm{O}-, \quad=\mathrm{C}-\mathrm{CH}_{2}-, \quad-\mathrm{O}-\mathrm{CH}_{3}\right), \quad 3.72-4.10 \quad\left(4 \mathrm{H},-\mathrm{COO}_{-} \mathrm{CH}_{2}-\right), 6.52 \quad(1 \mathrm{H} \times 0.47$, $-\mathrm{C}=\mathrm{CH}-,(Z)), 6.74(1 \mathrm{H} \times 0.53,-\mathrm{C}=\mathrm{CH}-,(E)), 6.86-7.40\left(10 \mathrm{H},-\mathrm{C}_{6} \mathrm{H}_{5}\right) . \quad{ }^{13} \mathrm{C}-\mathrm{NMR}$ $\left(\mathrm{CDCl}_{3}, \delta\right.$, ppm): 19.3, 33.9, 44.9, 53.2, 58.9, 64.2, 68.5, 70.3, 71.8, 126.4, 126.7, $127.1,127.4,127.7,127.9,128.1,128.3,128.7,129.0,129.2,131.5,133.7,136.7$, 137.4, 137.6, 138.4, 139.8, 142.8, 171.4. IR (neat, $\mathrm{cm}^{-1}$ ): 3056, 3023, 2880, 1958, 1732, 1599, 1576, 1493, 1449, 1379, 1356, 1292, 1240, 1196, 1107, 1030, 928, 866, 766,700 . 


\section{Polymerization of 1 and 2}

To a flask equipped with a magnetic stirrer bar, a benzene solution of $2(0.60 \mathrm{M}, 1.7$ $\mathrm{mL}, 1.0 \mathrm{mmol}$ ) was introduced and the solvent was removed in vacuo. Then, $\mathrm{Pd}(\mathrm{OAc})_{2}(0.0034 \mathrm{~g}, 0.015 \mathrm{mmol}), \mathrm{P}(o \text {-tolyl })_{3}(0.018 \mathrm{~g}, 0.060 \mathrm{mmol})$, and 1,4-dioxane $(1.0 \mathrm{~mL})$ were introduced and the mixture was stirred for $10 \mathrm{~min}$. After addition of p-bromophenylallene $(1,0.097 \mathrm{~g}, 0.50 \mathrm{mmol})$, the reaction mixture was heated at $80^{\circ} \mathrm{C}$ for $15 \mathrm{~h}$. After addition of water, the product was extracted with chloroform and the chloroform solution was concentrated and precipitated into hexane to give a polymer $(3)$ in an $87 \%$ yield $(0.19 \mathrm{~g}, 0.43 \mathrm{mmol}) .{ }^{1} \mathrm{H}-\mathrm{NMR}\left(\mathrm{CDCl}_{3}, \delta, \mathrm{ppm}\right): 1.10$ $1.33\left(3 \mathrm{H}, \mathrm{CH}_{3}-\right), 3.07-4.08\left(12 \mathrm{H}+2 \mathrm{H}+6 \mathrm{H}+4 \mathrm{H},-\mathrm{CO}_{2}-\mathrm{C}-\mathrm{CH}_{2}-\mathrm{O}-\mathrm{CH}_{2} \mathrm{CH}_{2}-\mathrm{O}-,=\mathrm{C}-\mathrm{CH}_{2-}\right.$, $\left.-\mathrm{O}-\mathrm{CH}_{3}, \quad-\mathrm{COO}-\mathrm{CH}_{2}-\right), 6.40-6.45 \quad(1 \mathrm{H} \times 0.32,-\mathrm{C}=\mathrm{CH}-, \quad(\mathrm{Z})), 6.62-6.72 \quad(1 \mathrm{H} \times 0.68$, $-\mathrm{C}=\mathrm{CH}-,(E)), 6.83-7.36\left(4 \mathrm{H},-\mathrm{C}_{6} \mathrm{H}_{4}\right) .{ }^{13} \mathrm{C}-\mathrm{NMR}\left(\mathrm{CDCl}_{3}, \delta, \mathrm{ppm}\right): 19.2,33.7,44.8$, 53.1, 58.8, 64.1, 68.5, 70.3, 71.8, 126.9, 127.4, 128.3, 128.5, 128.7, 129.3, 131.1, $133.0,133.3,135.7,136.6,137.1,137.5,138.1,138.3,141.1,171.3$. IR (neat, $\mathrm{cm}^{-1}$ ): 2880, 1732, 1628, 1510, 1456, 1379, 1356, 1292, 1240, 1198, 1107, 1028, 957, 868, 754,666 .

\section{Results and Discussion}

The polymerization of $\mathbf{1}$ and $\mathbf{2}$ was performed in the presence of $\mathrm{Pd}(\mathrm{OAc})_{2} / 4 \mathrm{P}(o-$ tolyl $)_{3}(3 \mathrm{~mol} \%)$ in 1,4 -dioxane at $80{ }^{\circ} \mathrm{C}$ for $15 \mathrm{~h}$. An objective polymer, a derivative of PPV having oligo-oxyethylene units, was obtained in a high yield (87\%) by precipitation into hexane. The number-average molecular weight $\left(M_{\mathrm{n}}\right)$ and the molecular weight distribution $\left(M_{\mathrm{w}} / M_{\mathrm{n}}\right)$ of $\mathbf{3}$ were estimated as 8,600 and 1.76, respectively, by GPC using polystyrene calibration curves. Reflecting upon the character of the oligo-oxyethylene units attached to the vinylene moieties, the polymer (3) exhibited good solubility in organic solvents such as benzene, THF, chloroform, $N, N$-dimethylformamide, and methanol. Under the analogous conditions, model compounds, stilbene derivatives having oligo-oxyethylene units (4), were obtained in an $89 \%$ isolated yield by the reaction of phenylallene, bromobenzene, and 2. The high efficiency of the model reaction strongly supported that the threecomponent coupling polymerization proceeds selectively under the examined conditions. The structure of $\mathbf{3}$ was supported by the spectroscopic analyses in comparison with those of 4 . In the ${ }^{1} \mathrm{H}$ NMR spectrum of $\mathbf{4}$, peaks attributable to the vinyl protons were observable at $6.52 \mathrm{ppm}$ and $6.74 \mathrm{ppm}$ for $E$ - and $Z$-isomers, respectively, where the ratio of $E: Z$ was determined as 53:47 from their peak intensities (Figure 1a). Likewise, the geometry of the olefinic structure in $\mathbf{3}$ was determined to be $68: 32$ from the peaks at $6.4 \mathrm{ppm}$ and $6.7 \mathrm{ppm}$ in its ${ }^{1} \mathrm{H}$ NMR spectrum (Figure 1b).

In the UV-vis spectrum of $\mathbf{3}$, the absorption maximum $\left(\lambda_{\max }\right)$ was observed at $317 \mathrm{~nm}$ which was about $50 \mathrm{~nm}$ bathochromically shifted in comparison with the corresponding model compounds $\left(4, \lambda_{\max }=265 \mathrm{~nm}\right)$ and was almost comparable to that of a PPV derivative prepared previously by the polymerization of $\mathbf{1}$ with sodium diethyl methylmalonate $\left(\lambda_{\max }=320 \mathrm{~nm}\right)[2 \mathrm{~d}]$. In the photoluminescence spectrum, $\mathbf{3}$ exhibited a blue light with an emission maximum of $451 \mathrm{~nm}$ upon the irradiation at $317 \mathrm{~nm}$ while no emission was observed in the case of the model compounds (4) (Figure 2). 
(a)
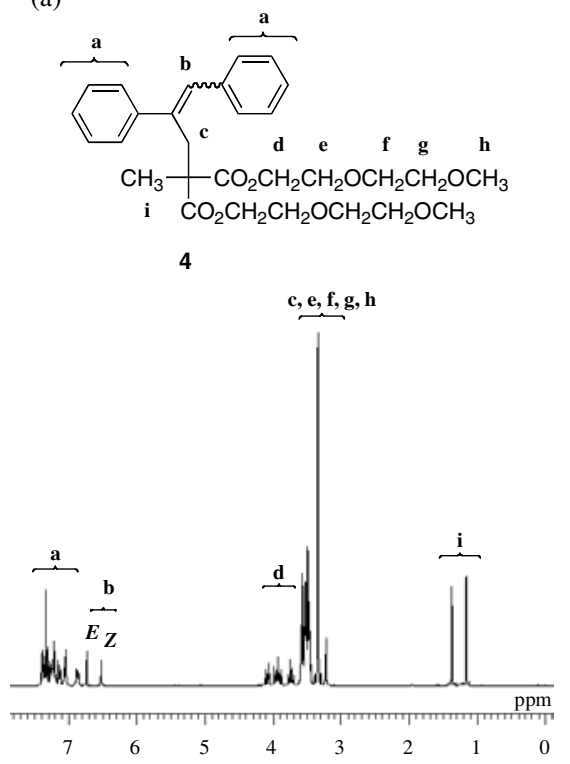

(b)

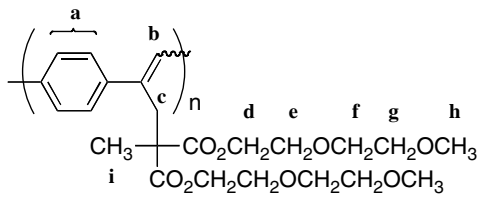

3

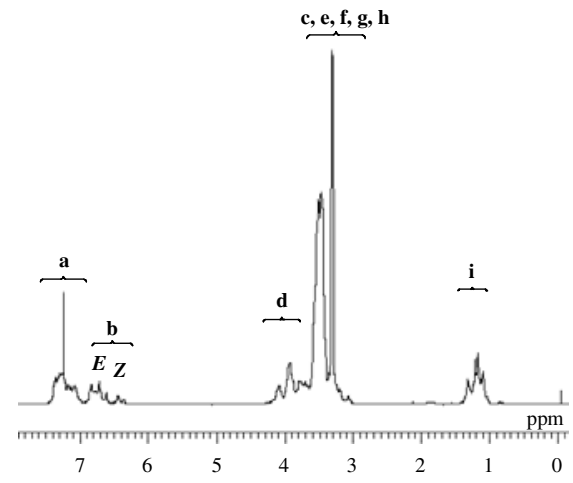

Figure 1. ${ }^{1} \mathrm{H}-\mathrm{NMR}$ spectra of $\mathbf{4}$ (a) and $\mathbf{3}$ (b).

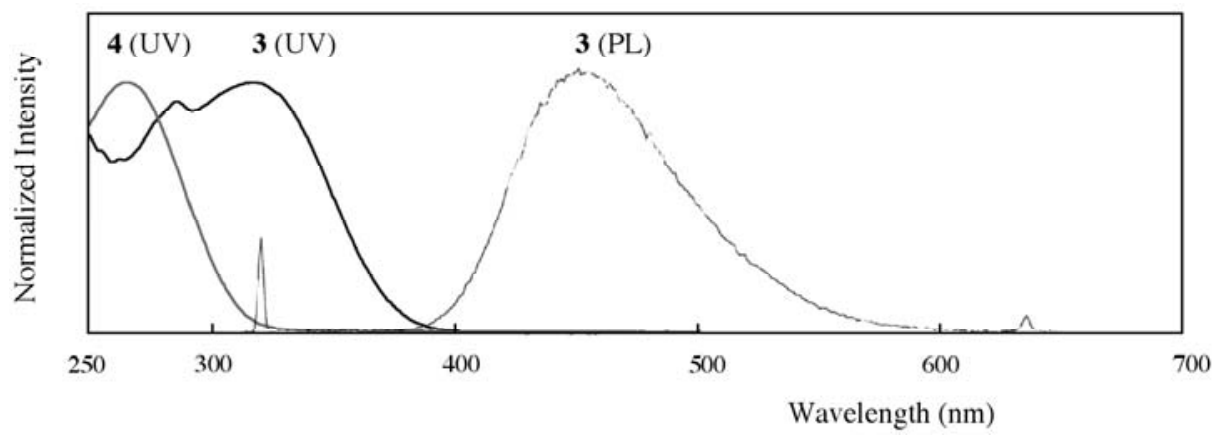

Figure 2. UV-vis absorption spectra and photoluminescence (PL) spectra of $\mathbf{3}$ and $\mathbf{4}$ measured in $\mathrm{CHCl}_{3}$.

\section{Conclusions}

The poly(p-phenylene-vinylene) derivative having good solubility in organic solvents was obtained from simple monomer systems by the three-component coupling polymerization of p-bromophenylallene and a nucleophile possessing amphiphilic oligo-oxyethylene units. Because the PPV derivative obtained in this study exhibits good solubility in polar solvents, its applications as a $\pi$-conjugated material in polar media (e.g., electrogenerated chemiluminescence device [6]) are currently being investigated.

Acknowledgements. The research was supported in parts by the Ministry of Education, Science, Sports, and Culture, Grant-in Aid for Scientific Research (C), 1365093, 2001-2003. 


\section{References and Notes}

1. For the review, see for example: Kraft A, Grimsdale CG, Holmes AB (1998) Angew Chem Int Ed Engl 37:402

2. (a) Miyaki N, Tomita I, Endo T (2006) Macromolecules 29:6685 (b) Miyaki N, Tomita I, Kido J, Endo T (1997) Macromolecules 30:6685 (c) Miyaki N, Tomita I, Endo T (1997) Polym Bull 39:677 (d) Miyaki N, Tomita I, Endo T (1997) Chem Lett 685 (e) Miyaki N, Tomita I, Endo T (1997) J Polym Sci Part A: Polym Chem 35:2097 (f) Miyaki N, Tomita I, Endo T (1997) J Polym Sci Part A: Polym Chem 35:1211 (g) Choi C-K, Tomita I, Endo T (2000) Macromolecules 33:1487 (h) Choi C-K, Tomita I, Endo T (2000) Polym Bull 44:137 (i) Ishibe S, Tomita I (2005) J Polym Sci: Part A: Polym Chem 43:3403

3. Analogous Three-Component Polycondensation systems have been independently described by Yokozawa et al, see: (a) Niimi L, Shiino K, Hiraoka S, Yokozawa T (1992) Macromolecules 35:3490 (b) Yokozawa T, Nakamura F (1995) Macromolecules 28:4668 (c) Yokozawa T, Takenoya K (1996) React Funct Polym 30:251 (d) Takenoya K, Yokozawa T (1998) Macromolecules 31:2906 (e) Yokozawa T, Niimi L, Takenoya K (1998) Macromol Chem Phys 199:2453 (f) Yokozawa T, Niimi L (2000) J Polym Sci Part A: Polym Chem 38:179 (g) Niimi L, Hiraoka S, Yokozawa T (2005) J Polym Sci Part A: Polym Chem 43:5440

4. (a) Shimizu I, Tsuji J (1984) Chem Lett. 233 (b) Ahmar M, Cazes B, Gore J (1984) Tetrahedron Lett 25:4505

5. Moreau JL, Gaudemar M (1976) J Organomet Chem 108:159

6. (a) Pei Q, Yu G, Zhang C, Yang Y, Heeger AJ (1995) Science 269:1086 (b) Yang Y, Pei Q (1997) J Appl Phys 81:3294 (c) Huang C, Huang W, Guo J, Yang CZ, Kang ET (2001) Polymer 42:3929 